\title{
Study on the Dimension of Tourism Ecology Based on the Construction of Beautiful New Hainan
}

\author{
Yuan Qi \\ University of Sanya, Sanya, Hainan, 572000
}

\author{
Keywords: Hainan, Tourism Ecology, Construction Method
}

\begin{abstract}
Hainan Island is China's largest special economic zone, but also an island province, ecological province, in China's tourism resources are not replicable excellent tourism resources.. Hainan international tourism island development strategy to further propose to tourism as a leader of the modern service industry has become an important pillar industry in Hainan economy. Hainan Island tourism planning in ten years to build the world's advanced level of international tourism island, time tight task, is a serious challenge, but it is an opportunity. Therefore, this paper chooses to study Hainan island tourism from the perspective of stakeholders, and to explore the relationship between tourism development model and the realization of interests of various stakeholders, taking Hainan Island as the research object of island tourism development model, and providing scientific decision-making Basis and related countermeasures. This is of great significance to the long-term, coordinated and sustainable development of Hainan Island tourism.
\end{abstract}

\section{Introduction}

Island tourism refers to the activities of sightseeing, leisure, recreation, excursions and vacations in the sea is lands and surrounding waters, and its vigorous rise is closely related to the development of coastal leisure tourism. Ecotourism in the island will occupy a more important place in the tourism industry. The history of the earliest island mass tourism took place in the century of England, but only confined to the British Isles near the area, the traffic is more convenient for the coastal islands and regions. After the century, due to the popularity of jetliners and the development of luxury cruise ships, coastal tourism from the developed areas of Europe to expand to the rest of the world. Governments with coastlines have made the island a valuable resource for the development of tourism. After entering the new century, the island tourism activities is to become a number of countries and regions important sources of income and tax sources. On the other hand, in the context of diversification of tourist destinations, the famous island area has become the most attractive tourist destination for tourists for several years. According to the China Tourism News published "annual tourism popular destination analysis report" shows that China's tourists favorite island tour, Southeast Asia and Hainan, China alternately become the first month of the popular destination. Southeast Asia is the year's most popular travel direction, Thailand, Singapore, Vietnam, Malaysia tourism and other key words in the forefront of the annual average; Boracay, Phuket and Brunei and other attention by the highest and more stable. Island tourism high-end brand image has been widely accepted by the world's tourists.

\section{The favorable conditions for the development of ecotourism in Beautiful New Hainan}

Hainan Province, including the administrative area of Hainan Island, Xisha Islands, the Nansha Islands island reef and its waters, the province's land mainly includes Hainan Island and Xisha, in the sand, Nansha Islands, the total area of 10,000 square kilometers, , The sea area of about 10,000 square kilometers. Hainan is located in the geographical location of Southeast Asia, backed by a huge mainland China market, close to Hong Kong and Macao, and Southeast Asian countries across the sea, easy to integrate into the Southeast Asian tourism circle. Hainan Province in the middle of the high four weeks low, by the mountains, hills, terraces, plains constitute a circular layered topography, cascade structure obvious. Hainan Province, developed waterways, relatively large rivers originated in the central mountains, composed of radial water system. The island alone into 
the sea of rivers, of which the catchment area of more than square kilometers of the article. Nandu River, Changhua River, Wanquan River for the three major rivers in Hainan Island, catchment area are more than square kilometers, the three river basin area accounted for the island area. Hainan good geographical location advantages and rich geographical conditions for the development of tourism in Hainan to provide a good environmental advantages. Hainan boasts rich biological resources and enjoys the reputation of "green treasure island". With a wide range of tropical plants, flowers, fruits and herbs, Hainan is the largest tropical gene bank of China.

Hainan Province has a good tropical island climate conditions, high quality coastal tourism resources, a variety of geothermal hot springs, rich tropical rain forest, unique island culture, all kinds of high quality tourism resources to build a rich and colorful tourism products provide a good foundation The As China's first ecological province, Hainan forest coverage rate, the atmospheric environmental quality index perennial to maintain a standard World Environmental Protection Organization announced the top ten global air quality cities, Sanya City ranked second, Haikou ranked fifth, all The water body as a whole or better than the national one or two standards. Since 2010, Hainan International Tourism Island as a whole image advertising every day in the CCTV, the Central People's Broadcasting Station, China Radio International and other national media broadcast, and has continued until the end of the year, only in the CCTV broadcast times more than times, In the CCTV "news network", "Chao Wen world" column before the broadcast, in the "Wanquan River clear and clear" light melody, "in order to good health, often to Hainan Island," the overall image of Hainan International Tourism Island Advertising show in the eyes of the national television audience, Hainan friends at home and abroad to send a permanent invitation. This is the first time in the national media in Hainan Province, such a large-scale, focused on the overall image of tourism promotion, the overall image of the international tourism island of Hainan propaganda, will stimulate domestic demand in Hainan, to expand consumption play an important role in promoting. At the same time, this is also on the construction of the international tourism island of a comprehensive promotion, will attract investors and tourists more concerned about Hainan.

In recent years, Hainan Province has been on the tourism market for a number of severe remediation, tourism market order improved significantly. Year, Hainan Province from the construction of international tourism island goal, in the province to vigorously promote Hainan tourism market special rectification "Sunshine Action" and the establishment of tourism police department, crack down on black corps, black guide, black car, black shop and other "four black" phenomenon, The legitimate rights and interests of domestic and foreign tourists, the eradication of all factors conducive to the construction of international tourism island for the construction of international tourism island to create a harmonious social environment and public opinion atmosphere of Hainan international tourism island image construction. "Sunshine Action" is Hainan's proposed construction of international tourism island after the first tourism market renovation activities. In this renovation activities, the public security departments to crack down on the illegal operation of the tourism market, disrupt the market order, social order and other criminal acts, timely investigation and prosecution of tourism security major case, to promote the tourism market social security comprehensive management of industrial and commercial departments To crack down on the "black corps", the streets to lure the illegal business behavior of tourists, the organization to fight against strong buying and selling and cheating the wrongdoing of consumers, investigate and deal with seafood stalls bullying cheers, scenic traffic traders entangled tourists selling goods behavior price department is responsible for investigation Tickets are high, high rebates, and price fraud and other violations of the traffic department is responsible for investigating the "black car", as well as illegal control of tourist vehicles, or driving up the price and other irregularities to ensure the quality of tourism vehicles, national and religious affairs departments responsible for the relevant departments On the tourist attractions of the vulgar culture and violation of national and religious policies, the use of feudal superstition to cheat the behavior of tourists to investigate and deal with.

\section{Promote Hainan ecotourism Transformation And Upgrading Measures}

Beautiful New Hainan ecotourism policy support. The government to expand tourism spending, 
increase budget development funding is limited to the development of tourism in Hainan, an important reason for the development of tourism in Hainan is still a very large development space, the development of space needs of the Hainan government to pay more manpower , Material and financial resources. In order to Hainan tourism into an international tourist island, and international standards, the Hainan government must be able to let go of the economy, and actively encourage the development of new tourism products and give economic support, according to the specific circumstances of infrastructure projects, to avoid blind investment Construction and bring the economic waste, each money must be implemented, put an end to cut corners, shoddy. In addition, the development of tourism in Hainan in urgent need of the central government in the funds and policies to give more concessions and support. As the country's largest special economic zones, but also the development potential of the largest special economic zones, policy and financial support can promote the development of tourism in Hainan more stable.

Beautiful New Hainan ecotourism legal support. Tourism market management chaos, disorderly state to the Hainan ecotourism industry has a very bad impact. First of all, the relevant departments must be aware of the seriousness of the problem, serious and responsible, and actively improve the correction. Be sure to do a clear job, a clear division of labor, the establishment and improvement of the relevant rules and regulations, the basic practitioners of the quality of practitioners and professional ethics training to enhance their sense of responsibility in the law enforcement and sense of responsibility, clear responsibility, do not shirk responsibility. Second, the choice of regular or surprise inspection of the various business outlets to observe compliance and discipline, and the establishment of incentive mechanisms, especially for travel agency business operations are not standardized behavior, to urge the travel agency to regulate their business operations, to develop a market The development of the law, do not violate the market order mechanism, industry regulations, improve the quality and level of law enforcement. Last, to strengthen the system governance, implement the tourist uncivilized behavior management method and the credit information recording system of the civil aviation passenger, establish the system of "red black list" of civilized tourism, and strengthen the consciousness of citizen civilization travel. To bring into play the function of creating activities to promote, by conducting "civilization tourism scenic area" competition and set up a "civilized" volunteer service station, optimization of the provincial tourism environment.

The nature and nostalgic elements of Beautiful New Hainan eco-tourism should be given priority. Hainan to build an international tourist island, the development of Hainan Island tourism, to the island's own resources and other natural endowment characteristics as the basis, the formation of complementary resources, distinctive tourist routes and development model. According to the regional characteristics, the inclination of the policy and the field investigation of the author, the idea of this paper is that the northern end of Haikou and the southern end of Sanya are the core tourist destination and destination of tourism, and give priority to the development of eastern Wenchang, Qionghai and Mausoleum Water line fashion, elegant coconut coast, the use of the region to attract foreign investment attractive advantages of the development of exhibition tourism, tourism, real estate, high-level golf resort. Hainan Island, the central region of the coastal property has weakened, should be more prominent characteristics of tropical tourism. Renovation of the existing Danzhou tropical ecological botanical garden, tropical spice crop research base, Wuzhishan National Forest Park and other distinctive tropical tourism resources. Highlight this area is different from the blue ocean, green ecology, red old area tourism concept color. The western region of Hainan Island is also relatively weak in the economic base of the region. Tourism resources are relatively poor, and long-term iron ore mining and environmental pollution has also been an urgent need to solve the short board. For this area, it is a low price, no limit loan purchase policy tied to the convalescent tourism real estate as the starting point, to create a health and health characteristics of the Chinese golden sunset coastline brand. The whole of Hainan Island in Haikou, Sanya, under the leadership of two core cities to Hainan International Tourism Island as a brand platform to natural pollution-free natural environment as the basis, to support the island tourism, small satellite groups and towns for the characteristics, Hainan island tourism to achieve the sea and the sea, the colorful development model. 
Deciding of red line of ecological protection is the basis for overall planning of Hainan Province. The red line of ecological protection means strictly controlled boundaries in key ecological function zones, ecological environmental sensitive areas and ecological environmental vulnerable areas according to relevant laws. It is divided into No Red Line and Restricted Red Line areas. In No Red Line area, any development and construction are prohibited in principle. However in Restricted Red Line Area, the development intensity is strictly controlled, and construction of industrial projects, exploitation of mineral resources, construction of houses and large scale farming are prohibited. It is reported that Hainan Province decides the red line of ecological protection based on scientifically and systematically assessing ecological service functions (including biodiversity protection, conservation of water and soil and water conservation) and ecological sensitivity in costal zones in Hainan and in line with harmonizing the conflicts among social and economic development program, urban and rural planning, overall plan for land utilization, environmental protection program and other industrial development plans. Henceforth, urban construction, industrial distribution and infrastructure layout of Hainan will comply with the deciding of the red line of ecological protection.

\section{Conclusion}

Building a beautiful new Hainan will have the awareness of ecological protection, forming a core - nature, multiple dimensions - policy, law and nostalgia, link of mountains and sea and connection of rivers and lakes will form, which in space, is in line with the frame of mountain shapes and water systems, and takes mountains and hills in middle mountainous region as cores, important lakes and reservoirs as space joints and galleries in nature reserve areas, main rivers and costal zones as ecological galleries. Ecotourism transformation will support for the development of the new Hainan province, which is to accelerate the construction of economic prosperity, social civilization, ecological livable and the people's happiness.

\section{Acknowledgement}

This paper is stage result of 2018 Hainan Province, colleges and universities in general science research project hold by associate professor Zhang Hongshuang "South China Sea Island ecological footprint of uninhabited resources".

\section{References}

[1] Cai Meng, Wang Yuming. Low-carbon tourism: a new way of tourism development [J]. Journal of Tourism. 2016 (01)

[2] Huang Wensheng. On low-carbon tourism and the creation of low-carbon tourist attractions [J]. Ecological Economics. 2015 (11)

[3] Ma Chi, Ding Junhui. Based on low-carbon tourism development strategy [J]. Modern Economy (Modern Property Second Half). 2013 (07)

[4] Liu Xiao. On low-carbon economy and low-carbon tourism [J]. China's collective economy. 2015 (13)

[5] Wang Li. Ecological moral education to achieve the path selection [J]. Tianjin Economy. 2007 (07)

[6] Wang Zhifa. Strategic thinking of the current development of tourism industry [J]. Journal of Tourism. 2014 (04) 